\title{
Assessment of Genetic Biodiversity of Several Traits Using SSR Markers in Rice (Oryza sativa L.)
}

\author{
Mahmoud Fazaa, Nessreen N. Bassuony, Walaa Essa, and David A Lightfoot²* \\ ${ }^{1}$ Rice Research and Training Center (RRTC), Sakha, Kafrelsheikh 2017, Egypt; ${ }^{2}$ Department of Plant, Soil \\ and Agricultural Systems, Southern Illinois University, Carbondale, IL 62901-4415, USA
}

Received: October 20, 2018 / Accepted: March 10, 2019

\begin{abstract}
Eight primers (RM 315, RM 318, RM 166, RM 302, RM 201, RM 234, RM 526 and RM 144) revealed different levels of polymorphism to tag the related traits of interest as tolerant to abiotic stress, resistant to biotic stress and yield-related traits. Two primers (RM 190 and RM 278) were monomorphic. The percentage of the polymorphism was nearly $80 \%$. The size of detected fragments ranged from 105-325 bp. A total of $\mathbf{1 8 6}$ bands were scored from the amplification products with the ten SSR primers. Genetic diversity analyses were conducted on the basis of the scores with 176 unique bands. Phylogenic tree for the fifteen rice accessions from each group were established according to the molecular data and based on ten SSRs. A marked genetic diversity was observed in these innovative accessions (Sakha 101, IR 03N137, IR 83142-12, IR 87856-10-AJY-1-B, HHZ 12-Y4DT1-Y2 and IR 1552), which revealed higher levels of diversity and hence can be used as donors for the effective conservation, utilization and providing favorable genes in rice breeding programs.
\end{abstract}

Keywords: Rice, Genotypes, Biodiversity, Evolution, SSRs.

* Corresponding author: ga4082@siu.edu

\section{Introduction}

In a set of ninety rice accessions divided into five groups were evaluated under normal and stress conditions. This work was divided into two parts: 1) Assessment of genetic biodiversity, which include phenotypic evaluation, genetic parameters, correlation coefficient estimation and morphological clustering for all the studied accessions. 2) Estimation of the genetic structure and divergence by utilizing marker assisted selection (MAS), SSRs to tag favorable quantitative trait loci, molecular profiling for establishing phylogenic tree to detect the origin/ evolution among all the tested accessions.

Assessment and estimation of genetic biodiversity and the discovery of evolved genotypes through the breeding process can bring a new point of view (Thomson et al., 2007). For finding out knowledge of multiple facets about rice and considering genetic diversity from phenotype to molecule which is essential for the effective conservation, utilization and providing favorable genes and valuable germplasm to be integrated into new varieties are vital to achieve advanced breeding.

Genetic biodiversity in a set of germplasm is very important for identifying new genes and for improvement of the germplasm. For this, many efforts have been made to assess the genetic diversity and relationships among germplasm collections of rice using DNA markers. Conserving agricultural diversity and assessment at the genetic level is a prerequisite for understanding the evolutionary patterns and developing suitable 
strategies for their conservation and sustainable use (Kumar et al., 2010).

Genetic relationship estimates based on data on the frequencies of alleles at specific microsatellite loci indicated that the majority of traditional varieties were poorly related to the improved varieties (Alvarez et al., 2007). Then, using SSRs markers which are simple tandemly repeated 5-20 fold; often ditto tetra-nucleotide; sequence motifs; each flanked by unique sequences, (IRGSP, 2005). These markers are valuable as genetic markers because: they are co-dominant in nature; show high polymorphism; are cost effective and easy to use in PCR; and used in automated genotyping.

Tens of thousands of potential SSRs have been identified in rice, and over 25,000 have been developed as molecular markers which are currently being used to develop high density genetic maps, genotype rice accessions, determine the genetic structure, optimize the assembly of core collections, and for marker-assisted selection in breeding programs.

The accessible genetic biodiversity whether natural or induced is a prerequisite for understanding the biological and evolutionary process of a particular set of rice accessions represented in a given geographical region or during the long-term domestication and cultivation under various ecological niches (IRRI, 2010). Rice accessions that are highly with divergent genetic background may help to speed up the breeding process to reach the status of new lines through proper crosses and backcrosses (Ferrero A, Vidotto F. 2010). Rice accessions with diverse genetic relationships will be used as innovative donors (e.g., resistant to biotic and tolerant to abiotic stresses) and donors for the effective conservation, utilization and providing favorable genes in rice breeding programs.

\section{Materials and Methods}

\section{Plant Materials}

Seeds of all the studied rice accessions were obtained from Rice Research and Training Center (RRTC) and from The International Network for Genetic and Evaluation of Rice (INGER) based at the International Rice Research Institute (IRRI). Genomic DNA was isolated from ninety rice accessions using CTAB (Cetyl-tetramethyl ammonium bromide), as described by Murray and Thompson, 1980 .

PCR amplification of SSR markers was carried out using ten primers and were carried out in $10 \mu \mathrm{l}$ volume., Accessions and primers are shown in tables 1 and 2, respectively. The accessions divided into five groups:

1. Cultivated varieties and promising lines: consisted of fifteen cultivated varieties and promising lines for rice production.

2. Conservation group: were divided into two subgroups (ex-situ \& in-situ)

2.A. Irrigated rice (ex-situ): consisted of fifteen earlymaturing accessions

2.B. Upland rice (in-situ): contained fifteen geneticallydiverse test accessions.
3. Soil stress tolerance: consisted of fifteen accessions for salinity tolerance

4. Green super rice: consisted of fifteen accessions for rice production

5. Blast resistance: consisted of fifteen blast monogenic lines for blast resistance.

The experiment was set in a randomized complete block design with 3 replications. For each accession, 20 seeds were planted in a greenhouse and leaves from 20-day old seedlings were collected for DNA extraction.

\section{Molecular Analysis}

\section{DNA Isolation and Quantification}

Total genomic DNA were isolated from young leaves grown in the green house for 15 days using CTAB method Muray and Tompson, 1980, quantification was carried out by gel based assay using different concentrations of $\lambda$ un-cut DNA.

\section{SSRs Based on Polymerase Chain Reactions}

PCR reactions for SSR markers were carried out in $10 \mathrm{ul}$ volume containing $1.0 \mu \mathrm{l}$ total genomic DNA $4.9 \mathrm{ul} \mathrm{H} 2 \mathrm{O}, 1.0$ $\mu 110$ X PCR buffer, $0.8 \mu 1 \mathrm{Mg} \mathrm{Cl} 2,0.4 \mu \mathrm{l}$ dNTPs, $0.3 \mu \mathrm{l} \mathrm{Taq}$ polymerase and $0.3 \mu \mathrm{l}$ from SSR markers (forward and reverse primers). Amplification was performed in Berkin Elemar Gene Amp PCR system 2400 and DNA Engine Peltier Thermal Circler with following the profile, $950 \mathrm{C}$ for $5 \mathrm{~min}$ (initial denaturation), $950 \mathrm{C}$ for $1 \mathrm{~min}, 550 \mathrm{C}$ for $1 \mathrm{~min}, 720 \mathrm{C}$ for $2 \mathrm{~min}$ and for 35 cycles with final extension $720 \mathrm{C}$ for $7 \mathrm{~min}$. was established, followed by storage at $4^{\circ} \mathrm{C}$. PCR thermocycler machines from Biometra and Applied Bio Systems were used (Chen et al., 2006).

Ten simple sequence repeats (SSR) primers were used according to the trait of interest in each group and subgroup,: RM 190 for thousand grain weight trait in group I. RM 315 for plant height trait and RM 318 for panicle length trait in subgroup II.A., RM 166 and RM 302 for drought tolerance trait in subgroup II.B., RM 201 and RM 234 for salinity tolerance trait in group III. RM 278 and RM 526 for grain yield related traits in group IV. and RM 144 for blast resistance trait in group V. These primers sequences were as shown in Table 2.

The PCR products were analyzed directly on $1.5 \%$ agarose gels in $0.5 \mathrm{x}$ TAE buffer, visualized by staining with ethidium bromide and Transillumination under ultra violet light. Comparison of accessions, based on the presence (1) or absence (0) of unique and shared polymorphic products was used to generate similarity coefficients using UPGMA method with statistical software package NTSYSpc2.1 (Rohlf, 2001).

The Polymorphism Information Content (PIC) value was calculated using the following formula: $\mathrm{PICi}=1-\sum(\mathrm{Pij}) 2$. Where $\mathrm{Pi}$ is the proportion of samples carrying the allele of a particular locus, $\mathrm{Pij}$ is the frequency of jth allele for i marker and the is for final score of all alleles for the given marker, (Botstein et al., 1980; Anderson et al., 1993). 
Table 1. Rice accessions for all five groups.

\begin{tabular}{|c|c|c|c|}
\hline \multicolumn{4}{|c|}{ Group I. } \\
\hline No. & Entry Name & Cross & Origin \\
\hline 1 & Sakha 101 & Milyang 79/Giza 176 & RRTC \\
\hline 2 & Sakha 104 & GZ 4100/GZ 4096 & RRTC \\
\hline 3 & Giza 177 & Pi No.4// Yumji No.1 / Giza 171 & RRTC \\
\hline 4 & GZ 10154-3-1-1-1 & Sakha 101/Sakha 105 & RRTC \\
\hline 5 & GZ 9399-4-1-1-2-1-2 & IR 65600/Giza 178 & RRTC \\
\hline 6 & Sakha 105 & GZ 4316/GZ 5581 & RRTC \\
\hline 7 & Sakha 106 & Hexi 30/Giza 177 & RRTC \\
\hline 8 & Sakha 102 & GZ 4120/GZ 4096 & RRTC \\
\hline 9 & GZ 10147-1-2-1-1 & IRI 385/GZ 6124-4-1-1-1 & RRTC \\
\hline 10 & GZ 9399-4-1-1-3-2-2 & IR 65600/Giza 178 & RRTC \\
\hline 11 & Giza 182 & Giza 181// IR 39422 - 163 -1-2 / Giza 181 & RRTC \\
\hline 12 & GZ 9461-1-4-2-3-1 & Dacw 2 Bayo/GZ 6296 & RRTC \\
\hline 13 & GZ 9807-6-3-2-1 & Yunlen 19/GZ $7102-20-82-1$ & RRTC \\
\hline 14 & Egyptian Jasmine & KDML 105/IR 262-43-8-11 & RRTC \\
\hline 15 & GZ 10101-5-1-1 & IRI 385/Sakha 103 & RRTC \\
\hline \multicolumn{4}{|c|}{ Group II. Subgroup II.A. } \\
\hline 1 & IR $03 \mathrm{~N} 137$ & IRRI 134/IR 70479-45-2-3//IR 64680-81-2-2-1-3 & IRRI \\
\hline 2 & HHZ 1-Y4-Y1 & HUANG-HUA-ZHAN* 2/YUE-XIANG-ZHAN & IRRI \\
\hline 3 & IR $02 \mathrm{~A} 127$ & IR00A 107/IR 62243-41-1-3-3 & IRRI \\
\hline 4 & IR $06 \mathrm{M} 147$ & MEM BERANO/PADI ABANG GOGO & IRRI \\
\hline 5 & IR $10 \mathrm{~N} 108$ & IR 65620-192-3-3-3-2/IR02N463//IR 72875-94-3-3-2 & IRRI \\
\hline 6 & IR 07A234 & NSIC RC 138/IRRI 123 & IRRI \\
\hline 7 & HHZ 12-DT 10-SAL 1-DT 1 & HUANG-HUA-ZHAN*2/TE QING & IRRI \\
\hline 8 & RI 1812084-8-1-1 & NEAMAT/IR 67014-138-3 & IRAN \\
\hline 9 & IR $06 \mathrm{~A} 181$ & IR 71718-59-1-2-3/IR 72 & IRRI \\
\hline 10 & IR $06 \mathrm{M} 143$ & MEM BERANO/PADI ABANG GOGO & IRRI \\
\hline 11 & HHZ 8-SAL6-SAL3-Y2 & HUANG-HUA-ZHAN*2/PHA LGUNA & IRRI \\
\hline 12 & IR $05 \mathrm{~N} 412$ & IR $72875-94-3-3-2 /$ IR $\quad 73707-45-3-2-3$ & IRRI \\
\hline 13 & IR $09 \mathrm{~N} 500$ & IR 66/IRRI 146 & IRRI \\
\hline 14 & BP 10620F-BB4-15-BB8 & CIHERANG/IR BB 64 & INDONESIA \\
\hline 15 & IR $06 \mathrm{~N} 119$ & IR 73707-45-3-2-3/IR 68552-100-1-2-2 & IRRI \\
\hline \multicolumn{4}{|c|}{ Group II. Subgroup II.B. } \\
\hline 1 & IR $83142-12$ & IR 06G103/IR 06G113 & IRRI \\
\hline 2 & IR $60080-46 \mathrm{~A}$ & IR 47686-08-4-3/CT $6516-21-4-4$ & IRRI \\
\hline 3 & IR $08 \mathrm{~L} 152$ & IR 78875-176-B-2/IR 78875-207-B-3 & IRRI \\
\hline 4 & IR 10L240 & IRRI 132/IR06L161 & IRRI \\
\hline 5 & IR $10 \mathrm{~L} 107$ & IR 70181-32-PMI $1-1-5-1 /$ IR $71700-247-1-1$ & IRRI \\
\hline 6 & IR 11L319 & IR06L142/IR1 1L101 & IRRI \\
\hline 7 & IR 11L290 & IRRI 119/BP 234 E-MR-11 & IRRI \\
\hline 8 & IR 11L276 & IRRI 119/IR11L101 & IRRI \\
\hline 9 & IR 10L411 & IR 78878-53-2-2-2/IR03A550 & IRRI \\
\hline 10 & IR 09L348 & IRRI 105/IR 78877-163-B-1-1 & IRRI \\
\hline 11 & IR 10L398 & IR06L161/IR 80508-B-57-3-B & IRRI \\
\hline 12 & IR 08L161 & IR 78875-176-B-2/IR 78875-207-B-3 & IRRI \\
\hline 13 & IR 11L301 & IR06L142/IR1 1L101 & IRRI \\
\hline 14 & IR 09L179 & IR 78878-53-2-2-2/CT 6510-24-1-2 & IRRI \\
\hline 15 & IR 09L173 & IR 78877-208-B-1-2/IRRI 148 & IRRI \\
\hline
\end{tabular}


Table 1. Continued.

\begin{tabular}{|c|c|c|c|}
\hline \multicolumn{4}{|c|}{ Group III. } \\
\hline 1 & IR 87856-10-AJY 1-B & AT 401/IR 03A550 & IRRI \\
\hline 2 & IR 87938-1-1-1-3-B & IR 4630-22-2-5-1-3/IR05N204 & IRRI \\
\hline 3 & IR 87938-1-1-2-2-B & IR 4630-22-2-5-1-3/IR05N204 & IRRI \\
\hline 4 & IR 87938-1-1-2-3-B & IR 4630-22-2-5-1-3/IR05N204 & IRRI \\
\hline 5 & IR $88300-2-2-1-B$ & IRRI 123/IR 66946-3R-178-1-1//A 69-1 & IRRI \\
\hline 6 & IR 86376-47-3-1-B & IR07F101/IRRI 126 & IRRI \\
\hline 7 & AT 401 & BG 94-1/POKKALI & SRI LANKA \\
\hline 8 & NONA BOKRA & - & INDIA \\
\hline 9 & POKKALI (ACC108921) & POKKALI & INDIA \\
\hline 10 & IR 85920-11-2-1-AJY1-3-B & IR 84087-19/IR00A110//IR00A110 & IRRI \\
\hline 11 & IR 85921-9-2-1-AJY1-1-B & IR 84087-29/IR00A110//IR00A110 & IRRI \\
\hline 12 & IR 87856-7-AJY1-B & AT 401/IR03A550 & IRRI \\
\hline 13 & IR 87938-1-1-1-2-B & IR 4630-22-2-5-1-3/IR05N204 & IRRI \\
\hline 14 & IR 88304-B-AJY1-B & IRRI 126/IRRI 135//IR 66946-3R-156-1-1///IR 55179-3B-11-3 & IRRI \\
\hline 15 & IR 88314-1-AJY1-B & IR $73718-23-2-1-3 * 2 /$ IR $\quad 66946-3 R-178-1-1$ & IRRI \\
\hline \multicolumn{4}{|c|}{ Group IV. } \\
\hline 1 & HHZ 12-Y4-DT 1-Y2 & HUANG-HUA-ZHAN*2/TE QING & IRRI \\
\hline 2 & HHZ 8-SAL9-DT2-Y2 & HUANG-HUA-ZHAN*2/PHA LGUNA & IRRI \\
\hline 3 & $\mathrm{KCD} 1$ & - & CHINA \\
\hline 4 & HHZ 11-Y6-Y2-SUB1 & HUANG-HUA-ZHAN*2/IR 64 & IRRI \\
\hline 5 & HHZ 10-DT7-Y1 & HUANG-HUA-ZHAN*2/ZHONG 413 & IRRI \\
\hline 6 & HHZ 12-Y4-DT 1-Y3 & HUANG-HUA-ZHAN*2/TE QING & IRRI \\
\hline 7 & HUA 564 & - & CHINA \\
\hline 8 & HHZ 5-Y4-SAL1-Y1 & HUANG-HUA-ZHAN*2/OM 1723 & IRRI \\
\hline 9 & HHZ 12-SAL2-Y3-Y2 & HUANG-HUA-ZHAN*2/TE QING & IRRI \\
\hline 10 & HHZ 5-SAL10-DT3-Y2 & HUANG-HUA-ZHAN*2/OM 1723 & IRRI \\
\hline 11 & HHZ 12-SAL8-Y1-Y2 & HUANG-HUA-ZHAN*2/TE QING & IRRI \\
\hline 12 & HHZ 12-SAL8-Y1-SAL1 & HUANG-HUA-ZHAN*2/TE QING & IRRI \\
\hline 13 & HHZ 5-DT7-Y3-SAL1 & HUANG-HUA-ZHAN*2/OM 1723 & IRRI \\
\hline 14 & HHZ 5-DT20-DT3-Y2 & HUANG-HUA-ZHAN*2/OM 1723 & IRRI \\
\hline 15 & HHZ 8-SAL14-SAL3-Y2 & HUANG-HUA-ZHAN*2/PHALGUNA & IRRI \\
\hline \multicolumn{4}{|c|}{ Group V. } \\
\hline 1 & IR 1552 & IR 160-25-1-1/CROSA 2 & IRRI \\
\hline 2 & B 40 & KAOHSIUNG 21//SERATUS MALAM/IR5 & IRRI \\
\hline 3 & IRRI 123 & IR 47761-27-1-3-6/IR 56381-139-2-2 & IRRI \\
\hline 4 & IR 78581-12-3-2-2 & IR 73012-137-2-2-2/PSB RC 10 & IRRI \\
\hline 5 & IR 11A208 & IR00A 107/IR 72875-94-3-3-2 & IRRI \\
\hline 6 & IR $10 \mathrm{~A} 234$ & IR04A115/IR 72875-94-3-3-2//IRRI 135 & IRRI \\
\hline 7 & IR $10 \mathrm{~A} 231$ & IRRI 143/IR 73718-23-2-1-3//IR00A110 & IRRI \\
\hline 8 & IR $10 \mathrm{~A} 228$ & IR01A154/IR 72870-19-2-2-3//IRRI 123 & IRRI \\
\hline 9 & IR $10 \mathrm{~A} 227$ & IR01A154/IR 72870-19-2-2-3//IRRI 123 & IRRI \\
\hline 10 & IR $10 \mathrm{~N} 290$ & IR05N341/IR $64680-81-2-2-1-3$ & IRRI \\
\hline 11 & IR 10A 196 & IR04A285/IRRI 123 & IRRI \\
\hline 12 & IR $10 \mathrm{~N} 253$ & IR BB 60-1/IR 73711-130-1-3-1//IR 65450-173-2-1-1-3-3 & IRRI \\
\hline 13 & IR 10 N205 & IR 72906-32-1-3-3/IR 73712-68-3-1-2//IR 65450-173-2-1-1-3 & IRRI \\
\hline 14 & IR 12M101 & IR 64/IR 68144-2B-2-2-3-1-166 & IRRI \\
\hline 15 & IR $10 \mathrm{~A} 121$ & IR 72906-32-1-3-3/IR 72890-81-3-2 & IRRI \\
\hline
\end{tabular}


Table 2. Forward and reverse sequences of ten SSR primers.

\begin{tabular}{lll}
\hline Primer & Forward sequence & Reverse sequence \\
\hline RM190 & $5^{-}$ctttgtctatctcaagacac $3^{-}$ & $5^{-}$ttgcagatgttcttcctgatg $3^{-}$ \\
RM 315 & $5^{-}$gaggtacttcetccgtttcac $3^{-}$ & $5^{-}$agtcagctcactgtgcagtg $3^{-}$ \\
RM 318 & $5^{-}$gtacggaaaacatggtaggaag $3^{-}$ & $5^{-}$tcgagggaaggatctggtc $3^{-}$ \\
RM 166 & $5^{-}$ggtcctgggtcaataattgggttacc $3^{-}$ & $5^{-}$ttgctgcatgatcctaaaccgg $3^{-}$ \\
RM 302 & $5^{-}$tcatgtcatctaccatcacac $3^{-}$ & $5^{-}$atggagaagatggaatacttgc $3^{-}$ \\
RM 201 & $5^{-}$ctcgtttattacctacagtacc $3^{-}$ & $5^{-}$ctacctcctttctagaccgata $3^{-}$ \\
RM 234 & $5^{-}$acagtatccaaggccctgg $3^{-}$ & $5^{-}$acgtgagacaaagacggag $3^{-}$ \\
RM 278 & $5^{-}$gtagtgagcctaacaataatc $3^{-}$ & $5^{-}$tcaactcagcatctctgtcc $3^{-}$ \\
RM 526 & $5^{-}$cccaagcaatacgtccctag $3^{-}$ & $5^{-}$acctggtcatgacaaggagg $3^{-}$ \\
RM 144 & $5^{-}$tgccctggcgcaaatttgatcc $3^{-}$ & $5^{-}$gctagaggagatcagatggtagtgcatg $3^{-}$ \\
\hline
\end{tabular}

Group I: (Panel A)

$\begin{array}{llllllllllllllll}\mathrm{M} & 1 & 2 & 3 & 4 & 5 & 6 & 7 & 8 & 9 & 10 & 11 & 12 & 13 & 14 & 15\end{array}$

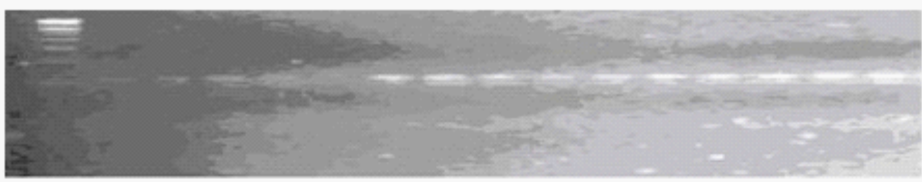

Panel A: SSR profile of the 15 accessions from group I. with RM 190. M= Ladder marker ( $50 \mathrm{bp}$ )

Group II. Subgroup 1. (Panel B and C).

$$
\begin{array}{llllllllllllllll}
M & 1 & 2 & 3 & 4 & 5 & 6 & 7 & 8 & 9 & 10 & 11 & 12 & 13 & 14 & 15
\end{array}
$$

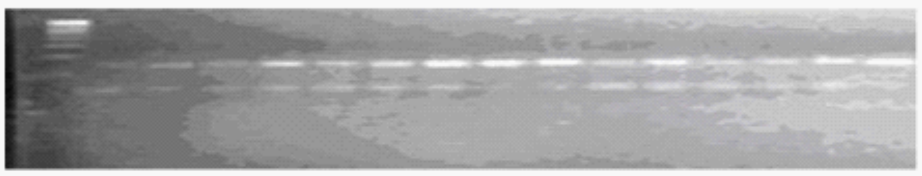

Panel B: SSR profile of the 15 accessions from group II.A. with RM $315 . \mathrm{M}=\mathrm{L}$ adder marker (50bp)

$$
\begin{array}{llllllllllllllll}
1 & 2 & 3 & 4 & 5 & 6 & 7 & 8 & 9 & 10 & 11 & 12 & 13 & 14 & 15 & M
\end{array}
$$

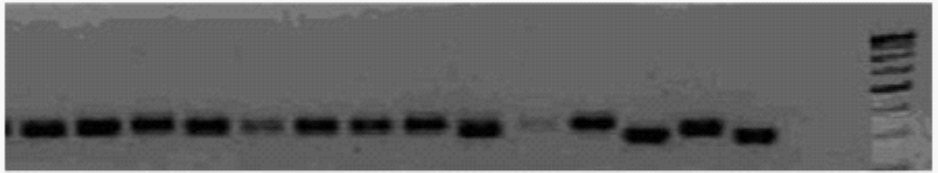

Panel C: SSR profile of the 15 accessions from group II.A. with RM 318. M= Ladder marker (50bp)

Group II. Subgroup 2. Panel D and E.

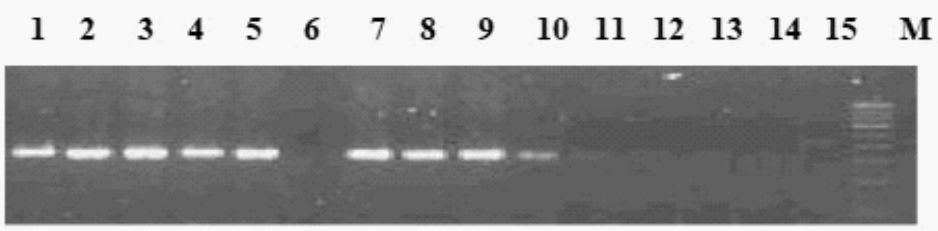

Panel D: SSR profile of the 15 accessions from group II.B. with RM 166. M= Ladder marker (50bp)

$$
\begin{array}{llllllllllllllll}
\mathrm{M} & 1 & 2 & 3 & 4 & 5 & 6 & 7 & 8 & 9 & 10 & 11 & 12 & 13 & 14 & 15
\end{array}
$$

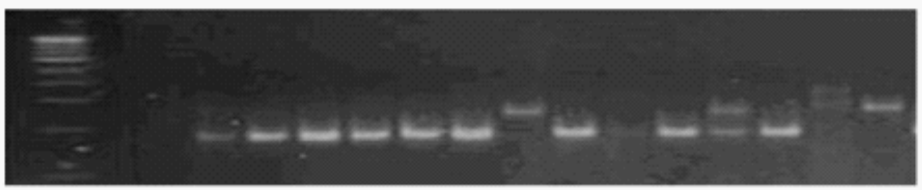

Panel E: SSR profile of the 15 accessions from group II.B. with RM 302. M= Ladder marker (50bp)

Figure 1. Panels A - J. 


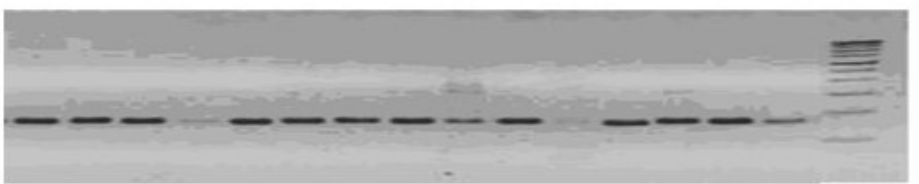

Panel F: SSR profile of the 15 accessions from group III. with RM 201. M= Ladder marker (50bp)

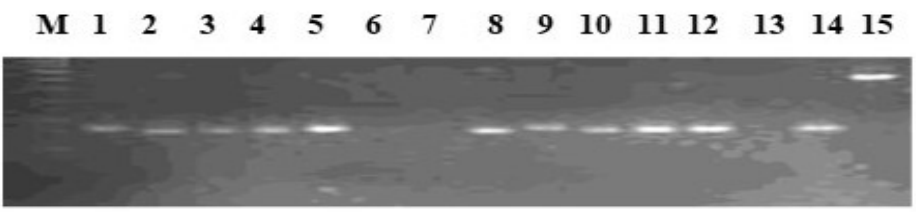

Panel G: SSR profile of the 15 accessions from group III. with RM 234. M=L adder marker (50bp)

Group IV: Panel (H and I).

$\begin{array}{llllllllllllllll}1 & 2 & 3 & 4 & 5 & 6 & 7 & 8 & 9 & 10 & 11 & 12 & 13 & 14 & 15 & M\end{array}$

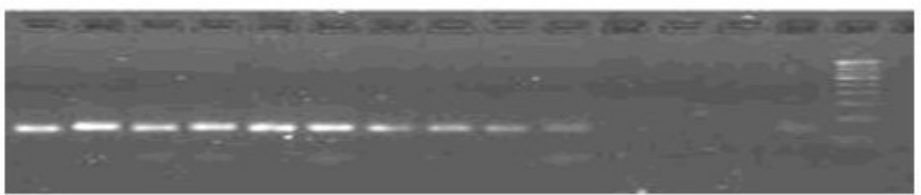

Panel H: SSR profile of the 15 accessions from group IV. with RM 278. M= Ladder marker (50bp)

$\begin{array}{llllllllllllllll}M & 1 & 2 & 3 & 4 & 5 & 6 & 7 & 8 & 9 & 10 & 11 & 12 & 13 & 14 & 15\end{array}$

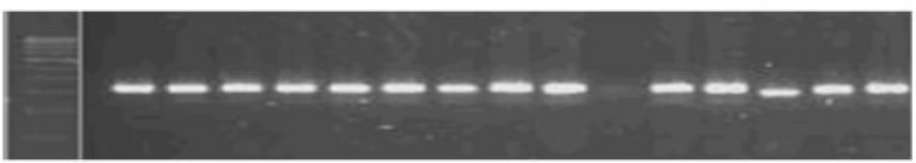

Panel I: SSR profile of the 15 accessions from group IV. with RM 526. M= Ladder marker (50bp)

Group V: (Panel J).

$$
\begin{array}{llllllllllllllll}
M & 1 & 2 & 3 & 4 & 5 & 6 & 7 & 8 & 9 & 10 & 11 & 12 & 13 & 14 & 15
\end{array}
$$

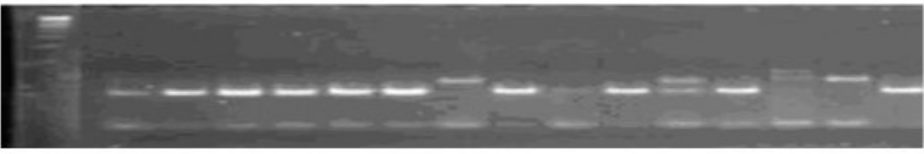

Panel J: SSR profile of the 15 accessions from group $\mathrm{V}$. with RM 144. M=L adder marker (50bp)

Figure 1. Continued.

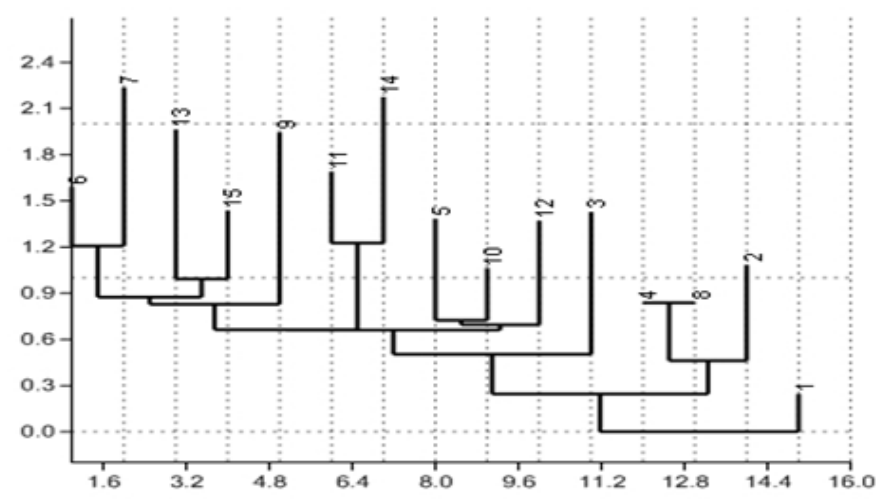

Figure 2. UPGMA dendrogram showing the phylogenic relationships among the accessions based on SSR markers. 
Table 3. Scoring data of 15 rice genotypes from each group against 10 SSRs.

\begin{tabular}{|c|c|c|c|c|c|c|c|c|c|}
\hline RM 190 & RM 315 & RM 318 & RM 166 & RM 302 & RM 201 & RM 234 & RM 278 & RM 526 & RM 144 \\
\hline & Group & Group & Group & Group & Group. & Group. & Group. & Group. & Group. \\
\hline Group 1 & 2. A. & 2. A. & 2. B. & 2. B. & 3 & 3 & 4 & 4 & 5 \\
\hline 1 & 1 & 1 & 1 & 1 & 2 & 1 & 1 & 1 & 1 \\
\hline 1 & 1 & 1 & 1 & 1 & 2 & 2 & 1 & 1 & 1 \\
\hline 1 & 2 & 1 & 1 & 1 & 1 & 2 & 1 & 2 & 1 \\
\hline 1 & 1 & 1 & 1 & 1 & 2 & 2 & 1 & 2 & 1 \\
\hline 1 & 2 & 1 & 1 & 1 & 2 & 1 & 1 & 2 & 1 \\
\hline 1 & 1 & 1 & 1 & 1 & 2 & 0 & 1 & 2 & 1 \\
\hline 1 & 1 & 1 & 1 & 2 & 2 & 0 & 1 & 2 & 2 \\
\hline 1 & 1 & 1 & 1 & 1 & 2 & 2 & 1 & 2 & 1 \\
\hline 1 & 1 & 1 & 1 & 1 & 2 & 1 & 1 & 3 & 0 \\
\hline 1 & 2 & 1 & 1 & 1 & 2 & 1 & 1 & 2 & 1 \\
\hline 1 & 2 & 1 & 1 & 0 & 2 & 1 & 1 & 2 & 2 \\
\hline 1 & 2 & 1 & 0 & 1 & 2 & 1 & 1 & 2 & 1 \\
\hline 1 & 2 & 1 & 1 & 0 & 2 & 0 & 1 & 2 & 0 \\
\hline 1 & 2 & 2 & 1 & 0 & 2 & 1 & 1 & 3 & 2 \\
\hline 1 & 2 & 1 & 1 & 1 & 2 & 0 & 1 & 2 & 1 \\
\hline
\end{tabular}

\section{Results and Discusson}

\section{Molecular Profiling for the Rice Accessions}

Ten primer pairs flanking simple sequence repeats which were used to determine the level of polymorphism among fifteen rice accessions in each tested group and subgroup, as shown in Figure 1 (Panels A-J). Eight primers (RM 315, RM 318, RM 166, RM 302, RM 201, RM 234, RM 526 and RM 144) were polymorphic to tag the related traits of interest as tolerant to abiotic, resistant to biotic stresses and grain yield. While, two primers (RM 190 and RM 278) were monomorphic. In group I: RM 190 was used for detecting major quantitative trait loci associated with thousand grain weight trait in the best selected accessions according to its morphological data. Only one fragment was detected in the range from 105 to $125 \mathrm{bp}$ as shown in Figure 1 (Panel A) and was monomorphic for this trait.

Regarding group II. - subgroup II.A. RM 315 and RM 318 primers which were used for detecting major quantitative trait loci associated with plant height and panicle length traits, respectively in the best selected accessions. For RM 315, a DNA fragment was generated with molecular size from 130 to 160 bp. monomorphic for plant height trait, as shown in Figure 1 (Panel B). RM 318 was used for observing major quantitative trait loci associated with panicle length trait and revealed polymorphic variation with fragment size ranged from 135 to 155 bp as shown in Figure 1 (Panel C).

DNA in in rice accessions for group II. - subgroup II.B. was amplified with RM 166 and RM 302 were used for observing major quantitative trait loci fragments associated with drought tolerance trait. RM 166 and RM 302 showed polymorphic variations with fragment size from 320 to $325 \mathrm{bp}$. and from 120 to $190 \mathrm{bp}$ as shown in Figure 1 (Panels D and E). RM 201 and RM 234 were used to tag major quantitative trait loci fragments related to saline tolerance trait in group III. DNA amplified two fragments with RM 201 and RM 234 which revealed polymorphic variations with the first fragment size which was ranged from 145 to $160 \mathrm{bp}$ while the second fragment was ranged from
130 to 165 bp as shown in Figure 1 (Panels F and G).

In group IV: RM 278 and RM 526 amplified two different fragments with size range from 130 to $145 \mathrm{bp}$ and from 240 to $266 \mathrm{bp}$., to tag major quantitative trait loci fragments associated with yielding in the fifteen rice accessions. RM 278 was monomorphic, while RM 526 revealed polymorphic variation as shown in Figure 1 (Panels H and I).

Considering group V: DNA from the fifteen rice accessions amplified with RM 144 to tag major quantitative trait loci associated with blast resistance trait. Amplified DNA fragments with RM 144 revealed polymorphic variations and was observed with size range from 215 to $255 \mathrm{bp}$ as shown in Figure 1 (Panel J).

Drive to conclusion that there was polymorphism to reveal diversity among accessions and validate known linked markers. Also, it may suggest a linkage between the chosen markers and valuable traits. These results agreed with those published earlier by (Islam et al., 2012; Lin et al., 2012).

\section{Estimation of Polymorphic Information Content}

Genetic polymorphism among rice accessions was established by using ten (SSR) Markers Seetharam et al., (2009) which recorded high level of polymorphism $(80 \%)$ number of alleles detected were for tagging major quantitative trait loci fragments associated with traits of interest as tolerant to abiotic, resistant to biotic stresses and grain yielding. Alleles ranged from 1 in case of RM 166 to 3 in case of RM 144). A total of 186 bands were scored from the amplification products with ten SSR primers. Genetic diversity analyses were conducted on the basis of the scores with 176 unique bands, as shown in Table 3 . The large range of polymorphism values for related accessions using SSRs provide greater confidence for the assessment of genetic diversity Meti et al. (2013).

Out of ten primers of SSR, eight primers were found to be polymorphic and Polymorphic information content (PIC) value was 0.827 . Polymorphism in rice accessions offer unique opportunity to study phylogenitic relationships and evolutionary comparisons and suggested that those markers that were highly 
variable at both the inter-subspecific and intra-subspecific characteristic and molecular levels, are very useful for distinguishing closely related accessions. These results agreed with those obtained previously by Das et al., (2013). These results agreed with those published earlier by Pachauri et al. 2013. It can be inferred from the result that a significant genetic diversity since high polymorphism has been detected among all accessions and thus there is a good possibility of genetic improvement using such a set of genotypes in rice breeding program.

\section{Phylogenic Relationships Among the Accessions Based on SSR Markers}

The phylogenic tree of fifteen rice accessions of each group and subgroup were established according to molecular data based on ten SSRs markers and constructed by Neighbor joining tree Cai et al., (2013). Rice accessions were clustered based on their banding patterns using UPGMA method largely on their genetic background and (Zhuoxian et al., 2014). The dendrogram is shown in Figure (2), which resulting from UPGMA analysis showed clusters of various sizes, Qianjin et al., (2006).

In group I. all fifteen accessions were diversified into various clusters, Sakha 101 was diversified earlier and was suggested to be an origin for the cultivated varieties and promising lines in this group. Two clusters were grouped into, $\mathrm{X} 1$ consisted of (Sakha 104, Sakha 102 and Gz 1015-3-1-1-1) while the cluster $\mathrm{X} 2$ consisted of eleven rice accessions grouped into four subclusters with (Giza 177) as out branch. Therefore, the latter supposed to be an origin for cluster X2. Sakha 105 and Sakha 106 diversified recently and these two accessions which actually have been used as new cultivated varieties.

Regarding group II. - subgroup II. A. IR 03N137 represented the origin for two clusters, $\mathrm{X} 1$ consisted of (HHZ 1-Y4-Y1, RI 1812084-8-1-1and IR 06M150), while X2 was divided into four sub-clusters with IR 02A127 accession as earlier diversified origin. while, subgroup II. B. the accession IR 83142-12 was diversified as an origin, X1 consisted of (IR 60080-46A, IR 11 L 276 and IR 10L240), while X2 consisted of four subclusters and accession IR 08L152 was diversified as an origin for cluster X2. Considering group. III., the accession IR 87856-10-AJY-1-B was revealed as an origin and the rest of the fifteen accessions were clustered into two clusters, X1 contained rice accessions (IR 87938-1-1-1-3-B, NONA BOKRA and IR 87938-1-1-2-3-B), while X2 consisted of four subclusters with IR 87938-1-1-2-2-B as out branch and supposed origin for cluster X2. In group IV. The accession HHZ 12-Y4DT1-Y2 was separated earlier as an origin, cluster X1 consisted of three accessions (HHZ 8-SAL9-DT2-Y2, HHZ 5-Y4-SAL1Y1 and HHZ 11-Y6-Y2-SUB1) while cluster X2 consisted of eleven rice accessions grouped into four sub-clusters. In group V. the accession IR 1552 was diversified earlier as an origin and lead to two clusters; cluster X1 with three accessions which were (B 40, IR 10A228, and IR 78581-12-3-2-2) while cluster $\mathrm{X} 2$ grouped into four sub-clusters with IRRI 123 as out branch. Sakha 101, IR 03N137, IR 83142-12, IR 87856-10-AJY-1-B, HHZ 12-Y4-DT1-Y2 and IR 1552 revealed higher levels of diversity and hence showed their ability to be used for effec- tive conservation, utilization and providing favorable genes and valuable germplasm for rice breeding. Morphological and molecular variations are very important since rice genotypes are highly domesticated. In fact, domestication process is accompanied by genetic erosion, which causes a reduction in genetic diversity among traditional varieties and gradual loss of genotypes, (Wang et al., 2014). Morphological and genetic diversity have occurred in rice during evolutionary process and residual overlaps of key genetic differences in different genotypes from different regions exit. SSR can therefore be used as remarkable tools to detect genetic diversity for breeding programs of rice.

\section{References}

Alvarez A, JL Fuentes, V Puldón, PJ Gómez, L Mora, MC Duque, G Gallego, and JM Tohme (2007) Genetic diversity analysis of Cuban traditional rice (Oryza sativa L.) varieties based on microsatellite markers, Genetics and Molecular Biology 30 (4): 1109-1117.

Botstein D, RL White, M Skolnick, and RW Davis (1980) Construction of genetic linkage map in man using restriction fragment length polymorphisms. Am J Hum Genet 32: 314-331.

Cai X, J Fan, Z Jiang, B Basso, and F Sala (2013) The puzzle of Italian rice origin and evolution: determining genetic divergence and affinity of rice germplasm from Italy and Asia. PLoS one 8 (11): e80351. doi:10.1371/Journal.Pone.008035.

Chen WY, HR Cui, JS Bao, XS Zhou, and SQ Yao (2006) A simplified rice DNA extraction protocol for PCR analysis. J. Rice Science 13 (1): 67-70.

Das, B., S. Sengupta, S. K. Parida, B. Roy, M. Ghosh, M. Prasad, and T. K. Ghose (2013). Genetic diversity and population structure of rice landraces from eastern and north eastern states of India. BMC Genet., 14: 71 .

Ferrero A and F Vidotto (2010) History of rice in Europe. In: SD Sharma. Rice Origin, Antiquity and History. USA: CRC Press. pp. 241-372.

IRRI (2010) Rice genetic diversity and discovery, International Rice Research Institute, the international rice genebank, http://irri.org/ our-work/research/genetic-diversity.

IRGSP (2005) The International Brachypodium Initiative, International Rice Genome Sequencing Project. The map based sequence of the rice genome. Nature 436 (7282): 793-800.

Islam A, SM Faridul, MR Ali., GB Gregorio, and MR Islam (2012) Genetic diversity analysis of stress tolerant rice (Oryza sativa L.) African Journal of Biotechnology 11 (85): 15123-15129.

Kumar S, IS Bisht, and KV Bhat (2010) Assessment of genetic diversity among rice (Oryza sativa L.) landrace populations under traditional production using microsatellite (SSR) markers. Electronic Journal of pPlant Breeding 1(4): 474-483.

Lin HY, YP Wu, AL Hour, SW Ho, FJ Wei, YIC Hsing, and YR Lin (2012) Genetic diversity of rice germplasm used in Taiwan breeding programs. Botanical Studies 53: 363-376.

Meti N, KC Samal, DN Bastia, and GR Rout (2013) Genetic diversity analysis in aromatic rice genotypes using microsatellite based simple sequence repeats (SSR) marker. African Journal of Biotechnology 12 (27): 4238-4250.

Murray AA and WF Thompson (1980) Rapid isolation of high molecular weight plant DNA. Nucleic Acid Res. 8: 4321-4325.

Pachauri V, N Taneja, P Vikram, NK Singh, and S Singh (2013) Molecular and morphological characterization of Indian farmers rice varieties (Oryza sativa L.), Australian Journal of Crop Science 7 (7): 923-932. 
Qianjin C, BR Lu, HJ Rong, F Sala, A Spada, and F Grassi (2006) Genetic diversity and origin of weedy rice (Oryza sativa f. spontanea) revealed by simple sequence repeat (SSR) markers. Annals of Botany 98: 1241-1252.

Rohlf FJ (2001) NTSYS-pc numerical taxonomy and multivariate analysis system. New York, USA: Exeter Software.

Seetharam K, S Thirumeni, and K Paramasivam (2009) Estimation of genetic diversity in rice (Oryza sativa L.) genotypes using SSR markers and morphological characters. African Journal of Biotechnology 8 (10): 2050-2059.

Thomson MJ, G Septinin, MS Endang, S Fatimah, TJ Silitonga, S Tiur, and SR Mccouch (2007) Genetic diversity analysis of traditional and improved Indonesian rice (Oryza sativa L.) germplasm using microsatellite markers. Theoretical and Applied Genetics 114 (3): 559-568.

Wang CH, XM Zheng, Q Xu, XP Yuan, L Huang, HF Zhou, XH Wei, and S Ge (2014) Genetic diversity and classification of Oryza sativa with emphasis on Chinese rice germplasm,. Heredity 112 (5): 489-96.

Zhuoxian H, X Jiang, D Ratnasekera, F Grassi, U Perera, BR Lu (2014) Gene flow promotes genetic diversity of weedy rice within populations: PLoS ONE 9 (12): e112778. doi:10.1371/Journal. Pone.0112778. 